\title{
A IMPORTÂNCIA DAS OUVIDORIAS PÚBLICAS MUNICIPAIS NA VISÃO DOS ESTUDANTES DO ENSINO MÉDIO: UM ESTUDO REALIZADO EM VICÊNCIA-PE
}

\author{
José Alisson de Oliveira ${ }^{1}$ \\ Jaciene Dias da Silva² \\ Rafaela de Lima Silva ${ }^{3}$ \\ Ana Elisabeth de Brito Alves ${ }^{4}$
}

\begin{abstract}
Resumo
Essa pesquisa reverbera a importância da Ouvidoria Pública como ferramenta de participação e intervenção da sociedade na Administração Pública, principalmente na visão dos estudantes do ensino médio, que estão em estágio para atuar como cidadãos, não apenas votando, mas participando, assimilando a importância desse serviço como um meio de interação, acolhimento de reclamações, denúncias, sugestões e elogios. O objetivo central desse trabalho é conhecer as opiniões de jovens estudantes do ensino médio sobre o serviço de Ouvidoria, de forma a elencar sugestões de melhorias para as secretarias, diretorias e departamentos do município em pesquisa, contribuindo assim para sua fluidez. O universo da pesquisa são duas escolas públicas estaduais da região, com uma amostra de 163 respondentes escolhidos aleatoriamente em sete turmas de $3^{\circ}$ ano. A pesquisa classifica-se como prática de natureza científica e bibliográfica. Tem caráter qualitativo-quantitativo, e como ferramenta metodológica foram aplicados questionários contendo doze perguntas em formato de escala de Thurstone. A pesquisa apresenta um resultado satisfatório, demonstrando graficamente uma crescente interação com relação às concordâncias com os pontos detalhados da escala, daí o conhecimento sobre a Ouvidoria Pública mostrada no resultado final: Concordâncias de $67,25 \%$ e Discordâncias de $32,75 \%$, ou seja, uma distância razoável e positiva de $34,5 \%$.
\end{abstract}

Palavras-chave: Fiscalização. Participação. Sugestão. Eficácia e Gestão.

DOI:10.37814/2594-5068.2020v3.p233-244

1 Graduando em Administração pela Faculdade de Ciências de Timbaúba. (alisson_oliveira0@hotmail.com)

2 Especialista em Administração Financeira e Controladoria pela Faculdade ESUDA. (jacyjd.silva@hotmail.com)

3 Graduanda em Administração pela Faculdade de Ciências de Timbaúba. (rafaela.liima@hotmail.com)

4 Professora Mestra da Faculdade de Ciências de Timbaúba. (anabritoalves@gmail.com) 


\begin{abstract}
This research reverberates the importance of Public Ombudsman as a tool for participation and intervention of society in public administration, mainly in the view of high school students, who are in the stage to act as citizens, not only voting but participating, assimilating the importance of this service as a means of interaction, reception of complaints, denunciations, suggestions and praise. The main objective of this work is to know the opinions of young high school students about the Ombudsman service, in order to list suggestions for improvements to the secretariats, directories and departments of the municipality in research, thus contributing to their fluidity. The research universe is two state public schools in the region, with a sample of 163 respondents chosen randomly in seven classes of the third year. The research is classified as a scientific and bibliographical practice. It has a qualitative-quantitative character and as a methodological tool were applied questionnaires containing twelve questions in Thurstone scale format. The research presents a satisfactory result graphically showing a growing interaction with respect to the agreements with the detailed points of the scale, hence the knowledge about the Public Ombudsman shown in the final result: Concordances of $67.25 \%$ and Discordances of $32.75 \%$, or a reasonable and positive distance of $34.5 \%$.
\end{abstract}

Keywords: Monitoring. Participation. Suggestion. Effectiveness and management. 


\section{INTRODUÇÃO}

O estudo vem procurar analisar a visão da sociedade estudantil, no que concerne aos estudantes concluintes do ensino médio, sobre a importância da Ouvidoria Pública Municipal, identificando dessa forma o conhecimento dos munícipes sobre Ouvidoria como instrumento de inclusão e participação social, não apenas votando, mas acompanhando e intervindo nas decisões da Administração Pública, o que é de fundamental importância para o momento atual.

A Ouvidoria Pública surgiu em 1809, na Suécia, com o objetivo de receber e encaminhar as queixas dos cidadãos contra os órgãos públicos. Nessa época, criou-se a palavra Ombudsman que, em sueco, significa representante do povo. Essa palavra surgiu para identificar o funcionário responsável por receber críticas e sugestões da população sobre órgãos públicos na Suécia. Sua missão é agir no interesse da população com os governos.

No Brasil, o surgimento da Ouvidoria está relacionado à implantação da administração colonial. Em meados do século XVI, foi nomeado o primeiro Ouvidor-Geral, para figurar como os "ouvidos do rei" e para garantir, como órgão do sistema de justiça, a rigorosa aplicação das "leis da metrópole". Com o processo de emancipação do País, esse instituto português acabou por ser extinto após a declaração de independência do Brasil, em 1822.

O trabalho visa averiguar o conhecimento do público em pesquisa com relação às realidades apresentadas, objetivando mudanças necessárias e aperfeiçoamento de ações com o debate sobre a importância desse serviço público, o qual gera uma importante e impactante discussão, e também ressalta relevantes pontos para serem analisados e sugeridos para o meio acadêmico e principalmente para a sociedade. Somado a isso, como justificativa desse estudo, o caminho percorrido sobre a importância da Ouvidoria Pública poderá resultar numa eficiente transformação na visão política e social do público pesquisado, visto que estão em preparação para adentrar na idade adulta, cientes de seus direitos e deveres para com a sociedade - seja como cidadãos ou futuros profissionais, é importante que sejam orientados desde já a prestar mais atenção ao que ocorre ao redor e como se encaminham os serviços públicos no seu município de origem. Aqui, se estenderão conceitos, orientações e demonstrações para a realidade da sociedade que ainda desconhece seu poder de participação na Administração Pública.

\section{OUVIDORIAS PÚBLICAS}

A Ouvidoria Pública surgiu pela primeira vez na Suécia em 1809, objetivando receber e encaminhar as queixas do povo contra o governo. A palavra Ombudsman, que em sueco significa "representante do povo", fora criada nessa época para intitular a pessoa que receberia as críticas e sugestões da sociedade, sendo dessa forma o canal entre o cidadão e o governo, com suas funções voltadas para garantir a participação e o diálogo para uma melhor gestão. A esse respeito, OLIVEIRA e MARTINS (2013) declaram:

As Ouvidorias estão sendo organizadas para que possam exercer um papel mais amplo, compartilhado com diferentes órgãos, com uma função específica de promover a realização 
de direitos pela mediação extrajudicial, sem judicializar conflitos, garantindo a comunicação entre os órgãos, melhorando procedimentos e políticas públicas. (p. 141)

Percebe-se que a Ouvidoria Pública atua como um agente promotor de mudanças, favorecendo uma Gestão flexível, que tem como compromisso a satisfação das necessidades do cidadão, e incita a qualidade nos serviços públicos garantindo informações e prestação de contas conforme a Lei de Acesso à Informação (Lei $n^{\circ} 12.527 / 2011$ ), pois essa tem ajudado a esclarecer os direitos e os deveres do cidadão e do governo, tendo a transparência como regra e o sigilo como exceção. A Ouvidoria possui um papel de prover acesso.

Consta no art. 37 da Carta Magna:

$\S 3^{\circ} \mathrm{A}$ lei disciplinará as formas de participação do usuário na Administração pública direta e indireta, regulando especialmente:

I - As reclamações relativas à prestação de serviços públicos em geral, asseguradas a manutenção de serviços de atendimento ao usuário e a avaliação periódica, externa e interna, da qualidade dos serviços.

Além disso, a Constituição consagrou no inciso XXXIII do art. $5^{\circ}$ que:

Todos têm direito a receber dos órgãos públicos informações de seu interesse particular, ou de interesse coletivo ou geral, que serão prestadas no prazo da lei, sob pena de responsabilidade, ressalvadas aquelas cujo sigilo seja imprescindível à segurança da sociedade e do Estado.

As Ouvidorias carregam consigo a responsabilidade de construir espaços plurais abertos para as demandas dos cidadãos, que são tão importantes no cenário público, elaborando um mecanismo de diálogo e participação social. Mediando o acesso a bens e serviços públicos e tendo na Gestão a oportunidade de aperfeiçoar suas perspectivas de conduta.

Segundo MINISTÉRIO DO PLANEJAMENTO; UNIÃO EUROPEIA (2012), "Quanto mais o cidadão participa, mais ele se torna capacitado para fazê-lo". O que não acontece no nosso País, região ou município, pois os usuários dos serviços de Ouvidoria Pública ainda não sabem usá-los, não são condicionados a saber fazer e nem quando precisam fazer, é uma questão de orientação e formação.

O Ouvidor deverá esclarecer aos cidadãos sobre seus direitos e deveres, despertando sua autonomia, potencial crítico, argumentatividade, ouvindo e compreendendo as diferentes formas de manifestação dos cidadãos, reconhecendo-os sem distinções, qualificando suas expectativas, identificando seus contextos, decodificando como uma importante oportunidade de melhoria, demonstrando os resultados alcançados, analisando a efetividade das respostas e gerando relatórios para subsídios.

\section{A GESTÃO PÚBLICA}

Os gestores têm sob sua responsabilidade bens que pertencem à sociedade e cuja gestão deve 
ser feita com elevado nível de compromisso, responsabilidade, transparência, ética e senso de justiça. Dessa maneira, MATIAS (2010) afirma:

[...] Destarte, identificamos que a gestão administrativa no uso de suas atribuições possui a responsabilidade de dirigir com ética os pertences do povo pelo qual foi escolhida para exercer honestamente tal função. Sabe-se que os processos administrativos são ininterruptos e, portanto, exigem clareza para com as tomadas de decisões, projetos e tudo o que rege os interesses sociais. Somado a isso, a gestão deve ser transparente por meio do Portal da Transparência do seu Município, contendo nele receitas, despesas e todas as informações que não são sigilosas, conforme a Lei de Acesso à Informação (Lei $\mathrm{n}^{\circ}$ 12.527/2011) [...].

O autor supracitado reverbera o senso de justiça que o poder público necessita ter perante a sociedade para uma prática igualitária e justa visando os direitos garantidos e os deveres cobrados, uma administração em consonância com os munícipes que cooperam para a eficácia dos trabalhos exercidos e as realizações dos projetos idealizados.

\section{O PLANEJAMENTO NA GESTÃO PÚBLICA}

De acordo com CHIAVENATO (2003), o planejamento público é idealizado para a execução ou implementação de uma operação ou atividade específica da organização, tem duração de curto prazo e constitui a formalização por meio dos processos e métodos de trabalho para cada plano operacional.

A partir do aparato acima, é possível identificar e concluir que o planejamento é indispensável para a realização da satisfação social, no setor público, oferecendo aos cidadãos serviços com qualidade, excelência e efetividade. Toda e qualquer ação deve ser preparada para se chegar ao desenvolvimento social dentro do sistema que fora antes arquitetado.

A Gestão Pública requer planejamento organizacional por intermédio da gestão que amplia as ferramentas de participação populacional e gerencia os projetos em consonância com os cidadãos para o avanço da sociedade. O governo deve intervir para possíveis e fundamentais mudanças no município com o objetivo de atender às demandas que resultam no bom desempenho da Administração Pública, o que se obtém com planos traçados e estudados.

Um dos destaques da Constituição Federal Brasileira de 1988 foi o Plano Plurianual (PPA), que é o instrumento inicial do planejamento governamental, descrevendo as finalidades e visões de futuro, os valores e os desafios da nação. A Administração Pública possui por competência a finalidade de atender às necessidades.

A Gestão que planeja está objetivando, aspirando e buscando realizar ações que beneficiem a sociedade como um todo, em que a efetividade social só seja permitida com a participação do cidadão, sendo fundamental que a Gestão Pública no uso de suas atribuições planeje a participação conforme vemos na ferramenta da Ouvidoria Pública. 


\section{ESTUDANTES DO ENSINO PÚBLICO DE NÍVEL MÉDIO}

As incertezas que, nos dias atuais, vêm prejudicando os jovens estudantes, descrentes muitas vezes no futuro e com uma percepção voltada apenas para o presente, passam por vezes despercebidas, quando a construção do futuro depende unicamente do presente que por eles é vivido tão intensamente. As mudanças são constantes, porém eles possuem uma ligeira facilidade de adaptar-se a novas situações e uma coragem incontestável de enfrentar os desafios. É nos jovens estudantes do ensino médio que a proposta deste estudo se embasa. A participação dos jovens na construção de uma nova sociedade é de fundamental importância, pois eles são os protagonistas de uma história que precisa dar certo. Segundo MELUCCI (1997):

Para a Juventude moderna, à relativa incerteza própria de sua idade, somam-se a incerteza e a transitoriedade derivada da variedade de cenários possíveis de futuro e, ao mesmo tempo, da impossibilidade cada vez maior de previsibilidade.

A escola moderna possui o desafio de aproximar o aluno do mundo contemporâneo, ela nasceu associada a determinadas circunstâncias sociais, políticas, econômicas e culturais que não podem passar despercebidas pela juventude, bem como não se pode privá-la de participar das decisões da sociedade, tendo em vista que, com a garra do presente, o futuro pode ser mudado. A renovação escolar não pode ser individual, precisa ser coletiva e social, enfatizando a democracia e colaborando na Administração Pública.

\section{A PARTICIPAÇÃO CIDADÃ NA GESTÃO MUNICIPAL}

Para SALLES (2010), "A existência de mecanismos de participação mantém os cidadãos ativos, atentos, e a representação faz com que os cidadãos deleguem completamente aos representantes o cuidado com a cidade". Sendo assim, o cidadão, quando usa os instrumentos de participação como the é garantido pela legislação, gera a possibilidade de se ter um governo mais democrático para alcançar objetivos comuns que favoreçam a todos de igual modo.

Quanto mais ele participa mais tende a conhecer os atos administrativos e cooperar com mais eficácia com suas opiniões e ideias, haja vista que a democratização é imprescindível para o País, os Estados e os Municípios.

O fortalecimento dos vínculos de participação e consequentemente de fiscalização geram resultados de um envolvimento social benéfico, resultando em melhoria nos serviços prestados pela Gestão administrativa. Não basta só ir contra uma ação do governo, é preciso intervir e apontar sugestões para solucionar problemas e qualificar serviços, é preciso ainda poder de percepção para delegar aos representantes legais da cidade as atitudes que devem ser tomadas para sanar as faIhas administrativas e para apontar os caminhos de aperfeiçoamento. Quem melhor pode falar dos problemas da rua? Da praça? Da escola? Da cidade? O cidadão fala com prioridade dos dramas que vivem no dia a dia e reconhecem as formas de acabar com cada transtorno, o que precisam é ser ouvidos e atendidos. 
O povo possui o poder de decisão perante os seus representantes, que foram escolhidos para administrar os bens de todos e em prol de todos, cuidando da população e suprindo suas necessidades. A fiscalização também é de extrema importância e precisa ser assumida pelo cidadão para averiguar os recursos públicos e sua correta utilização, favorecendo as mais diversas áreas, como saúde, educação, assistência social, segurança e tantas outras vias que regem a sociedade.

A participação, individual e coletiva, é fundamental para a manutenção do Estado democrático, sendo este não apenas o conjunto de instituições representativas, mas uma sociedade participativa. (FEDOZZI et al., 2012, p. 21)

Fica nítido que a participação cidadã está embasada na ação democrática que garante ao coletivo o poder de colaborar nos trabalhos elaborados pela Gestão pública, que atenta deve estar para ouvir a sociedade por meio da Ouvidoria.

Por meio do orçamento participativo é possível criar uma articulação eficiente entre Estado e sociedade, mesmo quando as relações predominantes do governo sejam inicialmente clientelistas.

Embora haja resistências de alguns governos à intervenção social, é possível atribuir relação que modifique os pensamentos deturpados no que se refere à participação do cidadão, município e sociedade, caminhando lado a lado por objetivos comuns, traçando metas, planejando, organizando, dirigindo, fiscalizando e obtendo os resultados esperados. (ALMEIDA, 2009, p. 7)

Os valores e modos administrativos vistos pela inserção da ferramenta da Ouvidoria renovam a Gestão Pública, promovendo o respeito e ampliando a relação do governo para com a sociedade. É preciso orientar e direcionar a população em geral, não só a focada em pesquisa neste estudo.

\section{PESQUISA}

\subsection{Metodologia}

De acordo com JUNG (2003), a pesquisa é o processo através do qual as pessoas adquirem um novo conhecimento sobre si mesmo ou sobre o mundo em que vivem, com a finalidade de responder a um questionamento, resolver um problema ou satisfazer uma necessidade.

Para o alcance do objetivo deste estudo, a pesquisa classifica-se como prática de natureza científica e bibliográfica. Tem caráter qualitativo-quantitativo e, como metodologia, foram aplicados questionários contendo doze perguntas em formato de escala de Thurstone.

Segundo OLIVEIRA (2001), a escala de Thurstone envolve métodos de cálculos sofisticados, consumindo bastante tempo, porém quando definida adequadamente é fácil de ser aplicada e respondida pelos indivíduos entrevistados. A construção da escala de Thurstone é inicialmente realizada através da elaboração de uma lista de frases, curtas e claras, que expressam opiniões, 
muito favoráveis e extremamente desfavoráveis, sobre assuntos relacionados com a atitude que se pretende medir. A distribuição das questões é feita por comparações favoráveis ou desfavoráveis, concordâncias ou discordâncias com determinadas afirmações.

Os questionários aplicados em sala de aula foram compostos por perguntas fechadas caracterizando sua percepção sobre Ouvidoria Pública do Município em pesquisa, colhendo seus pontos de vista bem como qual o conhecimento acerca do funcionamento dessa ferramenta e suas funções.

O público escolhido para ser avaliado pelo nosso questionário foram os alunos do $3^{\circ}$ ano, tendo em vista que já estão prestes a concluir o ensino médio e, para nós, saber sobre seus conhecimentos referentes à Ouvidoria é de extrema importância, bem como a possibilidade de introduzir esse assunto numa temática em sala de aula.

A pesquisa abrangeu 163 alunos de duas escolas estaduais do município escolhido; a tabela, referida à escala de Thurstone, relata o conhecimento dos alunos a respeito da importância e funcionamento da Ouvidoria Pública de sua localidade, através de um questionário com doze perguntas, indagando sobre diversos aspectos direcionados ao tema estudado.

\subsection{Resultados}

A pesquisa apontou que a maioria reconhece a importância dessa ferramenta, sendo verificadas suas análises de acordo com os questionários que obtinham informações por meio de: Concordâncias e Discordâncias. Essa proposta de entrevista foi apresentada para a Direção de cada escola, e na ocasião foi discutida a importância de levar a Ouvidoria Pública ao conhecimento em sala de aula, e assim alguns professores aplicaram conosco os questionários aos alunos, que responderam fisicamente e os entregaram, sendo feitos os cálculos dos resultados após a coleta das informações, turma por turma.

\section{FIGURA 1 - Questionário (Escala de Thurstone)}

\begin{tabular}{|l|l|l|}
\hline \multicolumn{2}{|l|}{$\begin{array}{l}\text { Assinale nas colunas da direita se você concorda ou discorda de cada uma das afirmações a seguir em relação a } \\
\text { Ouvidorias Públicas }\end{array}$} & CONCORDO (\%) \\
\hline AFIRMAÇÃO & $37,42 \%$ & $62,48 \%$ \\
\hline Ser monitorada pelas secretarias & $15,40 \%$ \\
\hline Acolher os munícipes através das formas de atendimento & $84,60 \%)$ \\
\hline $\begin{array}{l}\text { Fornecer informações de acordo com a Lei de Acesso à Infor- } \\
\text { mação (Lei no 12.527/2011) }\end{array}$ & $75,46 \%$ & $24,54 \%$ \\
\hline Intervir na relação entre o cidadão e a Gestão & $50,30 \%$ & $49,30 \%$ \\
\hline Acolher críticas, sugestões e elogios & $87,11 \%$ & $12,89 \%$ \\
\hline Receber e averiguar denúncias e reclamações & $90,18 \%$ & $9,82 \%$ \\
\hline Vistoriar o andamento da política do Município & $32,51 \%$ & $67,49 \%$ \\
\hline $\begin{array}{l}\text { Sugerir soluções para as Secretarias de acordo com as recla- } \\
\text { mações recebidas }\end{array}$ & $90,18 \%$ & $9,82 \%$ \\
\hline
\end{tabular}




\begin{tabular}{|l|l|l|}
\hline Ter como regra a transparência e o sigilo como exceção & $63,19 \%$ & $36,81 \%$ \\
\hline Estar atenta apenas para os interesses da Gestão & $72,39 \%$ & $27,61 \%$ \\
\hline Ser imparcial diante dos problemas expostos & $42,62 \%$ & $57,38 \%$ \\
\hline $\begin{array}{l}\text { Mudar a estrutura do Estado e criar conflitos entre o Poder } \\
\text { Executivo e o cidadão }\end{array}$ & $80,98 \%$ & $19,02 \%$ \\
\hline$\%$ Total (média) & $67,25 \%$ & $32,75 \%$ \\
\hline
\end{tabular}

Os estudantes do $3^{\circ}$ ano do ensino médio demonstraram em sua maioria $(90,18 \%$ de concordância) que a Ouvidoria Pública deve receber e averiguar denúncias e reclamações e dessa forma sugerir soluções para as secretarias de acordo com as reclamações acolhidas. Outro índice alto foi o de sugerir soluções para as secretarias de acordo com as reclamações recebidas $(90,18 \%$ de concordância); acolher crítica, soluções e elogios (87,11\% de concordância); acolher os munícipes através das formas de atendimento (84,60\% de concordância). Os casos de discordância, ficando claro o teor de entendimento, pois esses resultados indicam que não é realizado, o discordar é afirmar que não é feito como deveria, então os índices mais altos foram: Vistoriar o andamento da política do município $(67,49 \%$ de discordância) e que eles não têm como saber se essas Ouvidorias são monitoradas pelas secretarias às quais fazem correlação (62,48\% de discordância). Como o resultado gráfico mostra, a média aritmética das concordâncias foi de $67,25 \%$ e as discordâncias somam $32,75 \%$, ou seja, a distância razoável de $34,5 \%$ pode ser mais bem visualizada a seguir:

FIGURA 2 - Análise gráfica

$\%$ TOTAL (Média)

12. Mudar a estrutura do Estado e criar conflitos entre o Poder Executivo e o Cidadão

11. Ser imparcial diante dos problemas expostos

10. Estar atenta apenas para os interesses da Gestão

9. Ter como regra a Transparência e o sigilo como exceção

8. Sugerir soluções para as Secretarias de acordo com as reclamações recebidas

7. Vistoriar o andamento da Política do Município

6. Receber e averiguar denúncias e reclamações 5. Acolher críticas, sugestões e elogios

4. Intervir na relação entre o cidadão e a Gestão

3. Fornecer informação de acordo com a Lei de Acesso à Informação (Lei No 12.527/2011)

2. Acolher os Munícipes através das formas de atendimento 1. Ser monitorada pelas secretarias

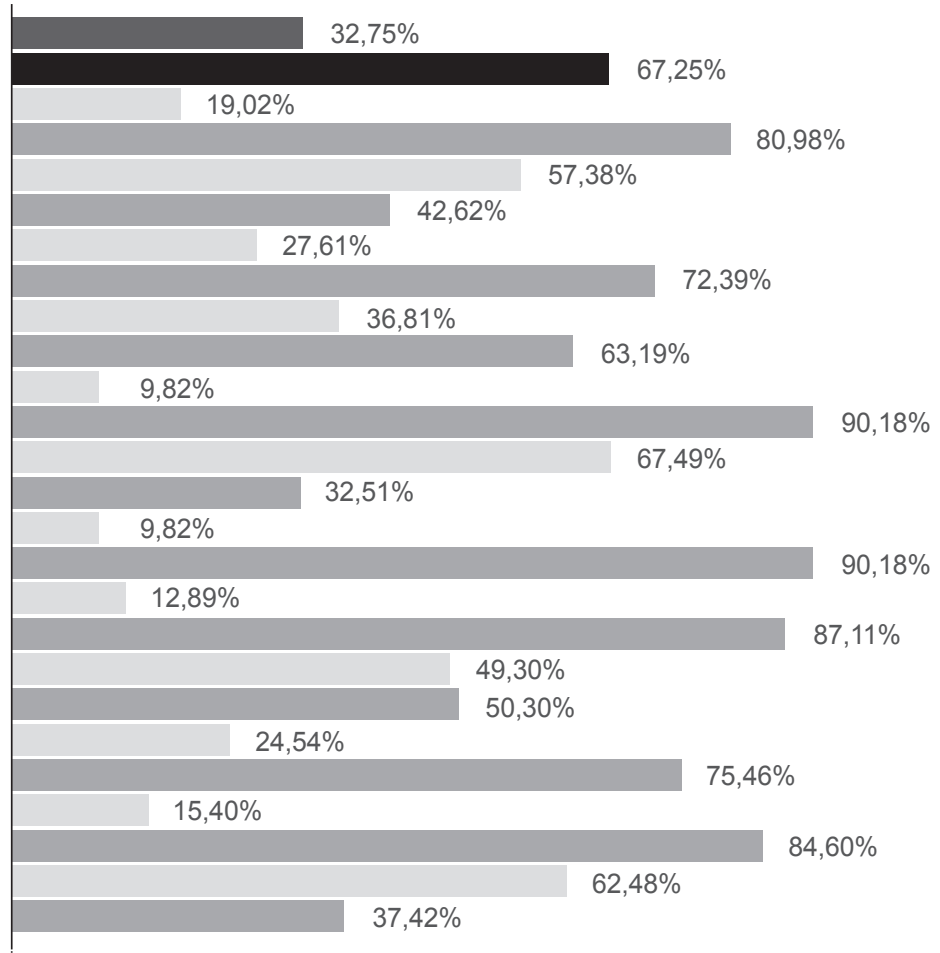

Discordo (\%)

Concordo $(\%)$ 
Alguns dos principais destaques vistos na pesquisa realizada por meio dos questionários foram: a Ouvidoria recebe reclamações e denúncias, sugere soluções para tais problemas e para melhorar o funcionamento da Administração Pública.

Nota-se na pesquisa que os questionados reconhecem a importância da Ouvidoria em intervir nos conflitos e ter como função acolher a sociedade de diversas formas de atendimento, mudando a estrutura do Estado sem criar conflitos entre os cidadãos e a Gestão. Os alunos consideram que a Ouvidoria não deve atentar apenas para os interesses da Gestão, mas sim mediar da melhor forma os conflitos existentes e encaminhar para a secretaria competente o problema e acompanhar sua solução para sanar problemas e tornar eficazes os trabalhos administrativos.

As funções atribuídas à Ouvidoria mais destacadas pelos estudantes enfatizam a tarefa de acoIher, sendo empática com os cidadãos, e encaminhar as situações sugerindo muitas vezes soluções e acompanhando cada problema. Para os estudantes, a Ouvidoria em síntese funciona como um importante canal de fiscalização e participação entre a sociedade e a Gestão.

\section{CONCLUSÕES}

O intuito foi de saber o que os jovens pré-universitários sabem e pensam sobre essa importante e fundamental ferramenta para os Cidadãos e para a Gestão. O objetivo também foi despertar os alunos para essa discussão que permite à sociedade a intervenção na Administração Pública, contribuindo com soluções, denunciando irregularidades e favorecendo o crescimento social. Além disso, esses objetivos desempenham um relevante processo educativo, pois atuam numa perspectiva informativa, fazendo conhecer os direitos assegurados por lei de que todos os cidadãos devem ter acesso à informação sobre os comandos da Gestão e participar para a efetividade de tais trabalhos, haja vista que não é só direito, mas também uma responsabilidade.

A Ouvidoria é indubitavelmente uma grande e importante ferramenta da Gestão pública e um canal essencial de participação dos cidadãos para fiscalizar, participar e colaborar dessa forma na Administração Pública. Tal implantação é um avanço na área da gestão democrática, existindo desafios a serem ultrapassados e passos a serem dados para melhor intervenção da sociedade nos rumos de seus municípios e de tudo o que rege seu funcionamento.

A Ouvidoria enfatiza que não basta apenas votar, é preciso participar e contribuir para a execução das políticas de todas as áreas, garantindo aos cidadãos o direito a saúde, educação, segurança e oportunidade de crescimento, com uma sociedade mais participativa e conhecedora de seus direitos e deveres.

Com os resultados apresentados, nota-se que os alunos do $3^{\circ}$ ano do ensino médio das escolas estaduais do município em pesquisa reconhecem a ferramenta da Ouvidoria, contudo este artigo propicia discutir a participação da sociedade no meio administrativo, sabendo-se que há muito a fazer e mais ainda a demonstrar sobre este meio que serve ao cidadão e à Gestão, mas é pouco usado, que deve ainda ser muito trabalhado e indicado, por sua importância e eficácia. 


\section{REFERÊNCIAS}

ALMEIDA, Lindijane de S. Bento. A questão da participação na gestão municipal de Mossoró-RN. In: XIV Congresso Brasileiro de Sociologia, 2009, Rio de Janeiro: Sociedade Brasileira de Sociologia, 2009.

BACHERO, M. Construindo outra sociedade: o capital social na estruturação de uma cultura política participativa no Brasil. Rev. Sociol. Polít., Curitiba, n. 21, p. 83-108, nov. 2003.

BRASIL. Constituição de 1988. Disponível em: www.ouvidorias.gov.br.

CHIAVENATO, Idalberto; SAPIRO, Arão. Planejamento estratégico: fundamentos e aplicações. Rio de Janeiro: Elsevier, 2003.

FEDOZZI, Luciano et al. Participação, cultura política e cidades. Sociologias, Porto Alegre, v. 14, n. 30, p. 14-44, 2012.

KLEBA, M. E., WENDHAUSEN, A. Empoderamento: Processo de fortalecimento dos sujeitos nos espaços de participação social e democratização política. Saúde e Sociedade, Rio de Janeiro, v. 18, n. 4, p. 733-743, 2009.

MATIAS PEREIRA, José. Curso de Administração Pública: Foco nas instituições e ações governamentais. 2. ed. São Paulo, SP: Editora Atlas, 2009.

MELUCI, Alberto. Juventude, tempo e movimentos sociais. Revista Brasileira de Educação, São Paulo, n. 5/6, p. 5-14, set./dez. 1997. (Juventude e Contemporaneidade, n. esp.)

MORIN, E. Os sete saberes necessários à educação do futuro. 3. ed. São Paulo: Cortez; Brasília: Unesco, 2001.

OLIVEIRA, T. M. V. Escalas de mensuração de atitudes: Thurstone, Osgood, Stapel, Likert, Guttman, Alpert. Fecap, v. 2, n. 2, 2001.

PAULINO, Fernando Oliveira; SILVA, Luiz Martins da (Org.). Comunicação Pública em debate: Ouvidoria e rádio. Brasília: Editora Universidade de Brasília, 2013.

SALLES, Helena da Motta. Gestão democrática e participativa. Florianópolis: Departamento de Ciências da Administração/UFSC, 2010.

SILVA, F. B.; JACCOUD, L.; BEGHIN, N. Políticas sociais no Brasil: participação social, conselhos e parcerias. In: JACCOUD, L. (Org.). Questão social e políticas sociais no Brasil contemporâneo. Brasília: Ipea, 2005. p. 373-407. 


\section{ANEXO}

\section{PRÉ-PROJETO: LEVANDO A OUVIDORIA PARA AS ESCOLAS \\ QUESTIONÁRIO SOBRE OUVIDORIA}

Ouvidoria é:

Ser monitorada pelas Secretarias.

Certo ( ) Errado ( )

Acolher os Munícipes através das formas de atendimento.

Certo ( ) Errado ( )

Fornecer informação de acordo com a Lei de Acesso à Informação (Lei no 12.527/2011).

Certo ( ) Errado ( )

Intervir na relação entre o Cidadão e a Gestão.

Certo ( ) Errado ( )

Acolher críticas, sugestões e elogios.

Certo ( ) Errado ( )

Receber e averiguar denúncias e reclamações.

Certo ( ) Errado ( )

Vistoriar o andamento da Política do Município.

Certo ( ) Errado ( )

Sugerir soluções para as Secretarias de acordo com as reclamações recebidas.

Certo ( ) Errado ( )

Ter como regra a Transparência e o sigilo como exceção.

Certo ( ) Errado ( )

Estar atenta apenas para os interesses da Gestão.

Certo ( ) Errado ( )

Ser imparcial diante dos problemas expostos.

Certo ( ) Errado ( )

Mudar a estrutura do Estado e criar conflitos entre o Poder Executivo e o Cidadão.

Certo ( ) Errado ( ) 